\title{
Responsible writing
}

\author{
Sudhir Kumar Thakur
}

Received: 27 September 2009 / Accepted: 27 October 2009

(C) Association of Surgeons of India 2010

I read your editorial 'Responsible Writing' with great interest [1].With more than 20 years of teaching experience in different medical colleges both in Govt and private sectors I would like to share my views with you. As far as the benchmarking of scientific writing is concerned it cannot be done precisely. It is not, for example $1 \mathrm{~kg}$ of sugar which will weigh $1 \mathrm{~kg}$ anywhere you go. All the quality indicators of any article like, journal impact factor, circulation number, indexation, journal citation report, web hits, manuscript acceptance rate, peer review etc., can be manipulated in one way or the other. This then raises the issue of the role of responsible writing to enhance the quality of an article. This again cannot be judged but responsible writing may be directly linked to an authentic representation of relevant datas. This habit of responsible writing has to be instilled in the formative years of an individual. English is the primary language of scientific communication and for majority of us it is a secondary language. Unless your English is proficient it is very difficult to process your thoughts and ideas coherently in words and sentences. With mushrooming of private medical colleges and the various policies of the Govt the standard of medical education has been compromised. Of course there are many exceptionally good teaching as well as non-teaching institutes which are encouraging medical tourism in the country, but they are not a true reflection of the prevailing conditions in our country. Unless we focus our attention on medical education we will not get doctors with a sense of responsibility whether for

\section{S. K. Thakur}

Department of General Surgery,

Santosh Hospital, Near Old Bus Stand,

Ghaziabad

E-mail: thakur_sk@rediffmail.com scientific writing or for patient care. With commercialisation of medical education this is going to be more difficult in the coming years. A good knowledge of medical computing and technical writing is also necessary for accurate representation of any work worth publication. I would like to quote from your earlier editorial. 'Is it a compulsion or desire to reveal something new and/or worthwhile. If it is compulsion, the paper will follow a pattern set in available literature. But if you are convinced about your positive efforts then publish the material before your zeal fades away [2]. If the writing is compulsive it may lack a sense of responsibility. This compulsive writing is going to increase in the near future, because of Medical Council of India (MCI's) recent decision of making publications compulsory for promotions [3]. Though this compulsion will definitely become passion for some of them. But, sometimes even after putting honest efforts one may not come up with any fruitful observations and then what?

Will such work find a place in any journal? Rarely, I think. This may then compel one to manipulate the data and to become dishonest.

I will conclude with a request to $\mathrm{MCI}$ for giving serious thoughts regarding inclusion of english language, medical computing and technical writing courses in undergraduate/ postgraduate curriculum so as to improve upon the body of published articles.

\section{References}

1. Satish Shukla (2009) Responsible writing. Indian J Surg 71:175-176

2. Satish Shukla (2007) How to write a scientific paper. Indian J Surg 69:43-46

3. Times News Network. Research work must to get promotion: MCI. N Delhi ed. of Times of India. 2009 Sept 23; page 18 (col. 5, 6) 